Saudi Journal of Pathology and Microbiology

Abbreviated Key Title: Saudi J Pathol Microbiol

ISSN 2518-3362 (Print) |ISSN 2518-3370 (Online)

Scholars Middle East Publishers, Dubai, United Arab Emirates

Journal homepage: http://scholarsmepub.com/sjpm/

Case Report

\title{
Fibroadenoma in Male Breast: A Case Report
}

Mohammad Shahid Iqbal $^{1 *}$, Abdul Hakeem Attar ${ }^{2}$, Aisha Tabassum ${ }^{1}$

${ }^{1}$ Assistant Professor, Department of Pathology, College of Applied Medical Sciences, Umm al Qura University, Makkah, Saudi Arabia

${ }^{2}$ Assistant Professor, Department of Haematology, ESIC Medical College, Kalaburagi Karnataka India

DOI: $10.36348 /$ sjpm.2019.v04i12.004

| Received: 06.12.2019 | Accepted: 22.12.2019| Published: 27.12.2019

*Corresponding author: Dr. Mohammad Shahid Iqbal

\section{Abstract}

Fibroadenoma of breast is very common in females, but a rarity in males. Gynecomastia and pseudogynecomastia is a common presentation. A case of fibroadenoma with concurrent gynecomastia in a young male is presented below.

Keywords: Fibroadenoma, Gynecomastia, Male breast.

Copyright @ 2019: This is an open-access article distributed under the terms of the Creative Commons Attribution license which permits unrestricted use, distribution, and reproduction in any medium for non-commercial use (NonCommercial, or CC-BY-NC) provided the original author and sources are credited.

\section{INTRODUCTION}

Fibroadenoma although very common in female breast, is a rare but well recognized and documented entity even in male breast $[1,2]$. Some authors have questioned the very existence of true fibroadenoma in male breast whereas a few believe that fibroadenoma of male breast are nodular foci of gynecomastia. Inspite of rarity, fibroadenoma of male breast have been reported sporadically in literature and there is also case series of 4 cases reported in literature by armed forces institute of pathology (AFIP) [3]. Most common association of male breast fibroadenoma is a concurrent gynecomastia. Gynecomastia and/or lobular differentiation have been known to coexist with male fibroadenomas and phyllodes tumors [2]. Here we present a rare case of fibroadenoma of male breast.

\section{CASE}

A male patient aged 25 years presented with right sided gynecomastia was referred for FNAC. On examination, a swelling measuring approximately $3 \times 2$ $\mathrm{cm}$, soft to firm in consistency and freely mobile was present in the right breast. There were no other abnormal findings (figure 1). The left breast was normal. FNAC was done and cytological smears showed many scattered bare bipolar nuclei and few stromal fragments and occasional stag-horn pattern arrangement of cell clusters. There was no cellular atypia (figure 2 and 3). A diagnosis of fibroadenoma was made based on the above findings. This patient underwent lumpectomy and a confirmatory diagnosis of fibroadenoma was made histopathology (figure 4).

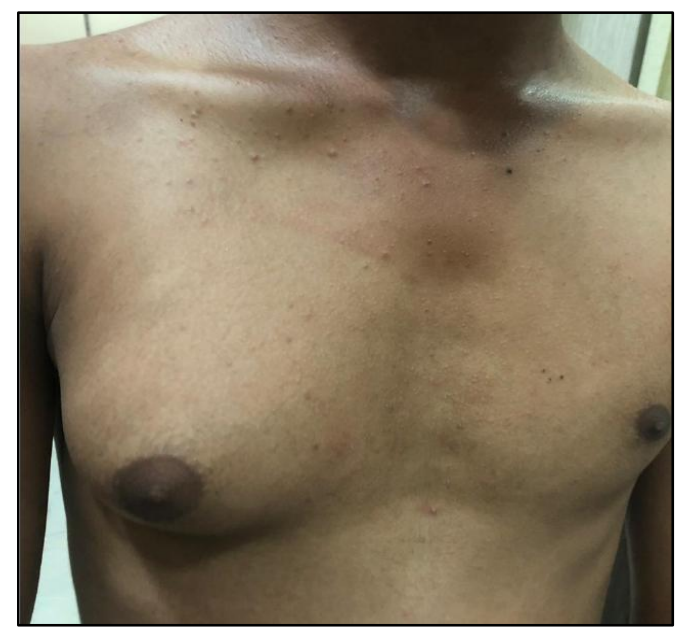

Fig-1: Gynecomastia of right breast

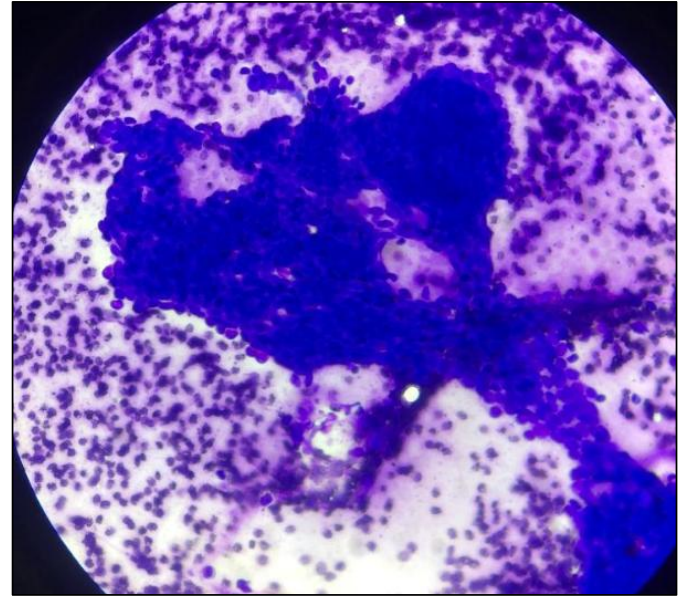

Fig-2: FNAC smear showing Stag-horn pattern: Giemsa (20X) 


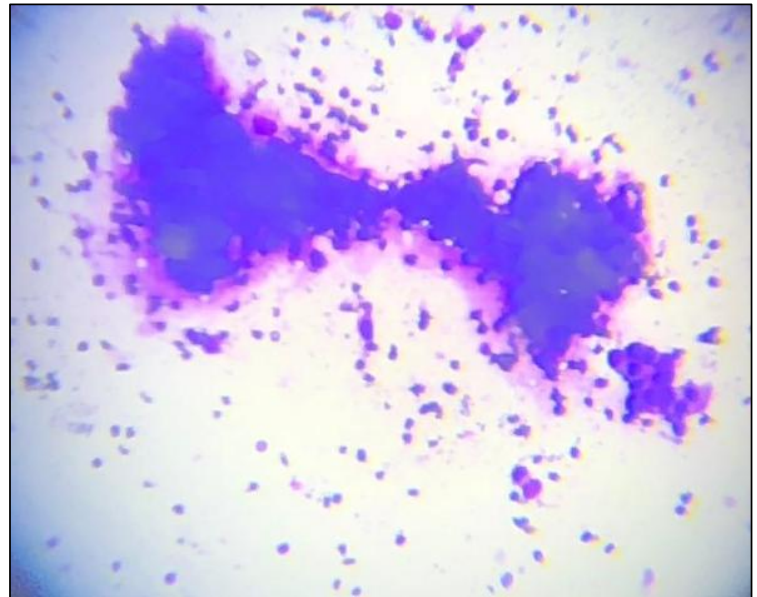

Fig-3: Bare bipolar nuclei (Giemsa: 20X)

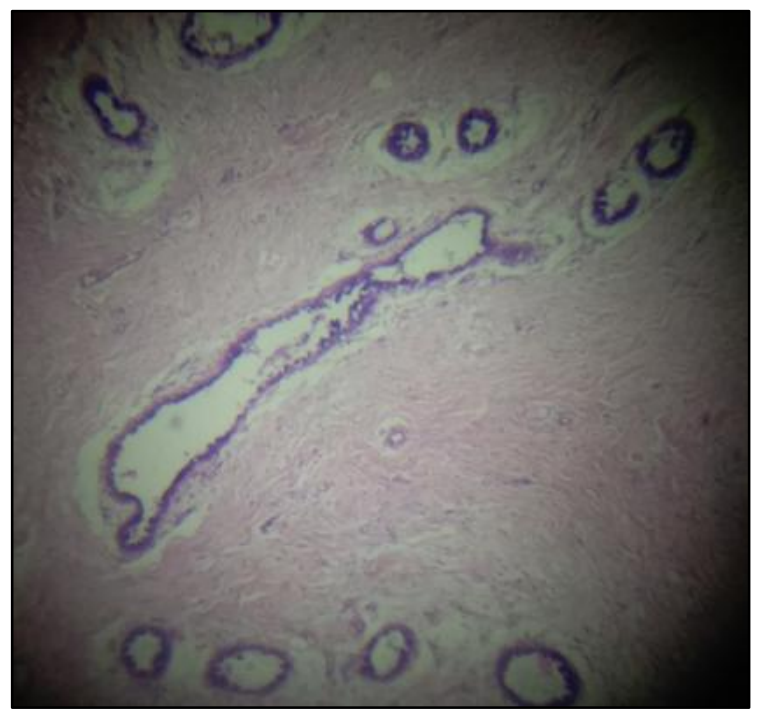

Fig-4: Proliferation of stromal and epithelial fragments (H \& E: 10X)

\section{DISCUSSION}

The male and female breasts are histologically and physiologically different. Male breast has variably sized ducts devoid of mammary lobules. The breast terminal duct lobular unit which is the site of female breast lesions is not well developed in males and this is the reason for rarity of male breast lesions [4].

Gynecomastia is a common entity with a prevalence of $30-70 \%$ among adults in different statistics [5]. It presents commonly as a discrete sub areolar swelling. It may be a physiological manifestation in development and may also be associated with variety of drugs [4]. There is benign proliferation of breast glandular tissue [5].

Increasing levels of obesity gives rise to pseudogynecomastia which has a high prevalence and it should be ruled out and with through history and there is no need for specialty referral [5].

The basic mechanism of gynecomastia in males is excess of estradiol which leads to breast proliferation. Most estradiol in men is derived from peripheral conversion of testosterone for adrenal estrone [5].

The percentage of men presenting with breast complaints has increased in the last 2 decades from 0.8 to $2.4 \%$ [6]. Breast mammography for male enlargement of breast is advised as $1 \%$ of all breast cancer cases are in men [6].

Carcinoma of male breast is a rare cause of enlargement and accounts for less than $1 \%$ of all breast cancer cases and $0.2 \%$ of all cancer in male patients [5].

Many single case reports of fibroadenoma are available in literature as well as a rare series of 4 cases of male fibroadenoma diagnosed on biopsy has been reported by armed forces institute of pathology (AFIP) $[7,8]$.

Fibroadenoma in male breast almost always occurs concurrently with gynecomastia. On FNAB, many stromal cells with bare bipolar nuclei are seen on smear. Many sheets of uniform single cells arranged in staghorn pattern are seen as honeycomb appearance [9].

FNAC of male breast lesions only few studies are there and most have described distinction between gynecomastia and carcinoma [3]. In a cytological study of 529 cases, 49 had 'fibroadenoma-like' picture. All 49 showed bare bipolar nuclei and stromal fragments. Epithelial atypia has also been reported in patients with fibroadenoma like picture [3]. FNA of 119 cases of male breast enlargement showed smears with variable cellularity ranging from virtually acellular to rich cellular smears. More cellular smears had a pattern similar to fibroadenoma [10]. There are varying opinions about the efficacy of FNAC in diagnosis of male breast lesions. Different cytological presentations within a gynecomastia can pose diagnostic problem in cytological diagnosis of fibroadenoma [3]. Unilateral male breast swelling is relatively common and definitive cytological diagnosis is infrequently obtained [5]. Biopsy is an investigation of choice for suspicious lesions which is associated with lower false negative and false positive rates as well as low incidence of pneumothorax [5].

FNAC of the male breast can present problems of diagnosis because the cytological assessment is often inadequate or occasionally can be confused with that of adenocarcinoma which might lead to unsatisfactory and repetitive investigation [5].

\section{CONCLUSION}

Fibroadenoma OD male breast is a definitive entity and not a myth. FNAC should be an integral part of initial assessment. FNAC is a reliable sensitive and specific technique which helps to avoid unnecessary surgery in lesions of male breast and should be 
performed as standard procedure in clinical evaluation of male breast lesions. To avoid missed diagnosis of male breast cancer, lymphoma or other pathological conditions, consideration should be given to tissue sampling or imaging in most cases of gynecomastia that present after puberty.

\section{REFERENCES}

1. Soomro I.N., Rashid, A., Skidmore, F.D. (1996). Fibroadenoma arising in the axilla of a male patient. Effect of high dose diethylstilboesterol. The Breast. 5 : 265-266

2. Shin, S.J., Rosen, P.P.(2007). Bilateral presentation of fibroadenoma with digital fibroma-like inclusions in the male breast. Arch Pathol Lab Med, 131: 1126-1129

3. Kusum, K., Kusum, V. (2002). Cytomorphological spectrum in gynecomastia: A study of 389 cases. Cytopathology, 13, 300-308

4. Voinee, O.C., Cirtoiu, M.M., Ion, D., Sajin, M., Damitru, A.V., Patrascu, O.M. (2018). Histology of male breast lesions. Series of cases and literature review. Medica-a Journal of clinical medicine, 13(3); 196-201
5. Rahman, S., Turton, P., Shaaba, A., Dall, B. (2011). Overview of gynecomastia in the modern era and the leeds gynecomastia investigation algorithm. The Breast Journal, 17(3) 246-255

6. Safak, K.Y. (2015). Mammography findings of male breast diseases. J Breast Health; 11.106-10

7. Gupta, P., Fosher, S., Garcia-Morales, F., Gray, T. (2011/2012). Fibroadenoma in male breast: case report and literature review. Breast Diseases; 33: 45-48

8. Yaghan, R.J., Bani-Hani, K.E. (2004). Male breast disorders in Jordan. Disease patterns and management problems. Saudi Med J 25(12), 1877 1883

9. Ashutosh, N., Virendra, K., Attri, P.C., Arati, S. (2013). Giant male fibroadenoma; A rare benign lesion. Indian J Surg, 75(sulppl 1):S353-355

10. Singh, R., Anshu., Sharma, S.M., Gangane, R.(2010). Spectrum of male breast lesions diagnosed by fine needle aspiration cytology: A 5 year experience at a tertiary care rural hospital in central India. Diagnostic cytopathology, 40(2), 113-117. 